\title{
FIRST INTERNATIONAL CONFERENCE OF YOUNG URBAN RESEARCHERS (FICYUrb) 2007*
}

Luís MENDES ${ }^{1}$

A First International Conference of Young Urban Researchers (FICYUrb) decorreu no Instituto Superior de Ciências do Trabalho e da Empresa (ISCTE) em Lisboa, nos dias 11 e 12 de Junho de 2007. A organização desta reunião científica ficou a cargo do Centro de Investigação e Estudos de Sociologia (CIES/ISCTE) em colaboração com a revista "Fórum Sociológico" da Faculdade de Ciências Sociais e Humanas da Universidade Nova de Lisboa (FCSH/UNL) e com o Instituto de Sociologia da Faculdade de Letras da Universidade do Porto (FLUP).

$\mathrm{O}$ evento nasceu da vontade de criar um espaço de reflexão interdisciplinar, objectivo audacioso mas plenamente cumprido no fim das jornadas. Pretendeu-se que o encontro fosse dinamizado por jovens investigadores em estudos urbanos que trabalhassem e desenvolvessem pesquisa nos temas da cidade. Privilegiou-se especialmente o trabalho de investigação daqueles que se encontravam a estudar em programas de pós-graduação, mas também dos que desenvolviam actividades de intervenção no espaço urbano: agências nacionais ou internacionais, organizações não governamentais ou municípios, por exemplo.

Foi igualmente objectivo da comissão organizadora que a conferência fosse um espaço de disseminação das recentes investigações provenientes das mais variadas áreas das ciências sociais sobre contextos urbanos, potenciando, assim, pela organização deste evento, a promoção e a constituição de redes interdisciplinares. Este objectivo foi prontamente atestado, não só pela diversidade de áreas científicas representadas numa ilustre comissão científica que concentrava nomes relevantes dos estudos urbanos nacionais e internacionais, provenientes da Sociologia, Geografia, Antropologia, Arquitectura e Economia, como também por uma pluralidade temática avançada inicialmente pela estruturação dos eixos da conferência em onze problemáticas diferentes.

Para além de fomentar o debate científico internacional, pretendeu-se, também, promover o encontro entre os jovens praticantes de estudos urbanos e investigadores e docentes com experiência na área, especialmente convidados para o encontro. A adesão ao call for papers desta primeira edição da conferência internacional foi esmagadora, com a inscrição de dezenas de participantes, com origens geográficas

* Recebido: 25/06/2007. Aceite: 22/08/2007.

1 Investigador do Centro de Estudos Geográficos da Universidade de Lisboa.

E-mail: luisfilipemendes@yahoo.com 
diversas, acompanhados por um número igualmente significativo de propostas de comunicação.

Embora inicialmente os onze eixos temáticos parecessem suficientes para agrupar, num esforço de coesão, a profusão de 170 comunicações e respectivos casos de estudo e problemáticas propostas, outros eixos foram sendo avançados ao longo das várias versões do programa da conferência, até à divulgação do calendário final. $\mathrm{Na}$ prática, a centena e meia de trabalhos realmente apresentados agregou-se em 39 painéis que ocupavam as manhãs e as tardes, numa média de cinco a decorrer em simultâneo, cada um com uma duração aproximada de 120 minutos, incluindo já o período de debate. Segue-se uma descrição sintética dos eixos temáticos e das respectivas questões-chave e problemáticas afectas.

1. ${ }^{\circ}$ eixo - Políticas, poder e processos de negociação. A cidade é um espaço de poder e de negociação. Que políticas definem e condicionam a vida nos territórios urbanos? Que relações de poder se encontram e negoceiam nos diferentes contextos urbanos de interacção? Que agentes - colectividades, movimentos sociais, associações fazem também a política na e da cidade?

2. ${ }^{\circ}$ eixo - Movimentos sociais: contextos e práticas culturais. Protagonistas da cidade são, também, os movimentos sociais, agentes fulcrais na definição de uma cidade contestatária e alternativa. Que circuitos e contextos de interacção e de sociabilidade são definidos por estes movimentos? Que referentes simbólicos são por estes criados? E que práticas sociais são por estes transformadas?

$3 .^{\circ}$ eixo - A comunicação e a mediação: relações complexas entre imigrantes $e$ instituições. Entre profissionais da administração e populações imigradas, diferentes interpretações da realidade geram respostas diversas nos dois lados da relação. Com que dificuldades se deparam os imigrantes no encontro institucional? Que estratégias de adaptação e de resistência são desenvolvidas para responder às dificuldades encontradas nessas situações?

$4^{\circ}{ }^{\circ}$ eixo - Economias informais em contextos urbanos. A informalidade como modo de vida alternativa à economia formal pode surgir como adaptação ou como resistência a sistemas formais impostos. Quais as regras e as linguagens da economia informal? Onde e como se manifestam? Quem são os seus actores e os seus beneficiários, dentro e fora do sistema institucionalizado?

$5 .^{\circ}$ eixo - Políticas, práticas e identidades culturais. As cidades são locais de diversidade e de efervescência cultural. Quais são as relações existentes entre as esferas artística ou cultural e os campos da economia, da política, etc.? De que forma se articulam as políticas europeias, nacionais e locais no processo de democratização da cultura? Que estratégias identitárias de negociação medeiam o nível das práticas e o das políticas em contexto urbano? Que papel desempenham variáveis como a classe, a etnia, o género, etc., na análise social das práticas culturais? Qual a relevância de modelos como os da "classe criativa" nas actuais dinâmicas económicas urbanas?

6. ${ }^{\circ}$ eixo - Espaços construídos, conflito e desigualdades sociais na cidade alargada. Conservação e mudança articulam-se e compõem-se em permanência nos projectos de construção e renovação do edificado urbano. Actores públicos e privados associam-se e opõem-se ao longo de processos de edificação cada vez mais pautados por grande visibilidade e objecto de intenso conflito. Como é que as práticas de edificação intervêm na criação de novos e velhos padrões de desigualdade social urbana? Que configurações de interesses e imagens da cidade - das populações metropolitanas, dos 
"usuários", dos "residentes", e dos espaços - são criadas e recriadas na construção social do espaço urbano?

7. ${ }^{\circ}$ eixo - Planeamento, design e usos do espaço urbano. As formas de como se organizam os espaços das cidades envolvem uma série de relações complexas entre os decisores políticos, os técnicos e as populações. Que tipo de negociações se levam a cabo entre as várias instâncias implicadas nestes processos? Qual o papel da arquitectura do espaço público nos nossos dias? Sabendo que existem desfasamentos entre a concepção do espaço e os seus usos quotidianos, que tipo de estratégias tecem tanto os urbanistas como as populações para negociar a organização do espaço?

$8 .^{\circ}$ eixo - Movimento, circulação e usos do espaço público urbano. Ontem como hoje, o movimento da cidade engendra políticas, saberes técnicos e experiências quotidianas que importa explorar. Desde os percursos pedonais até à circulação em vias rápidas, dos fluxos de informação até à recolha dos lixos urbanos, são múltiplos os contextos em que se pode analisar o modo como a cidade constitui e é constituída pelo movimento de informações, pessoas e bens. Que fluxos constroem os espaços urbanos - comummente chamados públicos, colectivos, exteriores - e através de que processos de ancoragem estes se fixam nos territórios?

9. ${ }^{\circ}$ eixo - Trabalho, território e organizações: reconfigurações e estilos de vida. À escala planetária a divisão social do trabalho intensifica-se e complexifica-se crescentemente. Desde a cidade industrial às actuais áreas metropolitanas, os espaços e os tempos de trabalho e as suas formas de organização reconfiguram-se em permanência (por exemplo, trabalho nocturno, trabalho a tempo parcial, segundo emprego, itinerância, teletrabalho, etc.). À interdependência entre a cidade central e a periférica, justapõem-se alterações nos estilos de vida? Que mudanças no mundo do trabalho se repercutem nas cidades e na sua organização espacial?

$10{ }^{\circ}$ eixo - Dispersão/Concentração: a socialização urbana na cidade estilhaçada. Concentração das elites em zonas específicas do território urbano e processos de guetização. A cidade surge-nos como um espaço socialmente segregado, marcado por bolsas de riqueza e pobreza (condomínios fechados, bairros populares em transformação, etc.). Que lógicas de distinção e que processos de segregação geram esta cidade estilhaçada? E que processos relacionais de transgressão diluem as fronteiras dentro da cidade?

11. ${ }^{\circ}$ eixo - Cidade-Mundo/Cidades do Mundo? Competição e hierarquia, diferenciação e fragmentação. O destino das cidades e dos territórios urbanos depende em muito das relações de competição e diferenciação que entre eles se desenvolvem a nível global. Como é que essas dinâmicas de inserção na economia mundial se compõem e articulam com os processos de diferenciação social, espacial e cultural presentes nos territórios urbanizados e nas suas crescentes zonas de influência? Neste quadro complexo, que novos e velhos modos de agir na cidade e na economia urbana são recriados? Quais os seus mais (ou menos) (in)visíveis protagonistas - actores públicos e privados, classes ou grupos, meios económicos ou culturais?

No fim do primeiro dia da conferência, o público presente teve ainda oportunidade de assistir ao lançamento do livro "À Escala Humana: Planeamento Urbano e Arquitectura de Habitação em Olivais Sul (Lisboa, 1959-1969), de João Pedro Silva Nunes. Logo de seguida, a organização procedeu à inauguração da exposição bibliográfica "A cidade e a rua". Se a cidade sempre despertou o interesse dos cientistas sociais, a rua enquanto unidade mínima desse espaço, raramente tem sido enfatizada. Muito poucas vezes a rua foi isolada e conceptualizada como um lugar e um território 
com características próprias, como palco e elemento estruturante de uma ampla variedade de relações sociais. Esta exposição teve como objectivo despertar o interesse para um espaço quotidianamente presente na vida dos citadinos, mas que permanece ainda muito pouco explorado e conhecido. Disciplinarmente ela organizou-se de uma forma muito abrangente, incluindo referências provenientes da História, da Arquitectura, da Geografia, da Sociologia, da Antropologia, tentando restituir um olhar o mais completo possível sobre a rua e a cidade, indo de encontro à reflexão de natureza interdisciplinar que desde o início presidiu aos trabalhos da FICYUrb 2007. Perante um tema tão amplo, o critério principal que orientou a escolha das obras apresentadas foi o da língua, destacando os trabalhos publicados em português, nas suas versões originais ou como traduções. Organizada pela Direcção de Serviços de Biblioteca e Documentação do ISCTE, esta exposição teve o apoio do CIES-ISCTE, da FCT e da FLAD.

Uma nota final de congratulação à comissão organizadora da FICYUrb 2007, pelo arrojo no lançamento desta empresa, que, para quem estava de fora, se afigurou um esforço organizativo muito intenso, não só pelo número de participantes, comunicações e subsequentes recursos materiais e imateriais que envolveu, bem como pelo recurso privilegiado e frutífero à Internet e a um inovador sistema informático de gestão de conferências. Suportado em software livre do Public Knowledge Project (http://pkp.sfu.ca/), este sistema permitiu gerir todo o processo de organização da conferência, incluindo a recepção de abstracts/artigos, a sua revisão e aceitação, a disponibilização das actas finais e o registo dos participantes. Foi compatível com as normas mais conhecidas de acesso livre à informação, embora não obrigasse à disponibilização livre dos materiais. 